\title{
Synthesis and application of carbon adsorbents in chromatographic separation of biologically active complexes
}

\author{
AR Kerimkulova ${ }^{1,2}$, Seitkhan Azat ${ }^{1,2 *}$, LM Manocha ${ }^{3}$, SM Manocha ${ }^{3}$, GE Zhusupova and $Z$ ZA Mansurov $^{1,2}$ \\ ${ }^{1}$ Institute of Combustion Problems, Almaty, Kazakhstan \\ ${ }^{2}$ KazNU Al-Farabi, Faculty of Chemistry and Chemical Technology, Almaty, Kazakhstan \\ ${ }^{3}$ DGGS IP University, Delhi, India
}

\begin{abstract}
Nanostructured carbon sorbents based on agricultural wastes, such as rice husk (RH), apricot kernel (AK), walnut shells (WS) are obtained. Sorption capacity in terms of specific surface area, methylene blue adsorption, electron microstructure of the surface and ultimate composition of obtained samples of carbon-based sorption material are investigated. Herbal substance "Limonidine" is isolated from plant roots of L. Gmelinii species of Limonium Mill genus using a column chromatography with nanocarbon sorbent. A possibility to use carbon-based sorption materials for separation and purification, as well as in various biologically active complexes (BAC) is described.
\end{abstract}

\section{Introduction}

The useful properties of activated carbon have been known since ancient times. This traces back to 1500 BC when Egyptians used charcoal as an adsorbent for medicinal purposes and a purifying agent. Around $420 \mathrm{BC}$ it was observed that Hippocrates dusted wounds with powdered charcoal to remove their odor. Ancient Hindu societies purified their water by filtration through charcoal. In 1773, the Swedish chemist Karl Wilhelm Scheele was the first to observe adsorption of gases on charcoal. A few years later activated carbons began being used in the sugar industry as a decolorizing agent for syrup.

In the early $20^{\text {th }}$ century the first plant to produce activated carbon industrially was built for use in sugar refining industry in Germany. Many other plants emerged in the early 1900's to produce activated carbons primarily for decolorization. During World War I activated carbon was used in gas masks for protection against hazardous gases and vapors.

Today, activated carbons are used to remove color from pharmaceutical and food products, as air pollution control devices for industrial and automobile exhaust, for chemical purification, and as electrodes in batteries. 500,000 tons per year of activated carbon are produced globally [1-3]. $80 \%$ of this is used for liquid phase applications, and $20 \%$ is used for solid phase applications.

Activated carbon (AC) is a unique material with its immense capacity for adsorption from gas and liquid phases. It occupies a special place in terms of producing a clean environment involving water purification as well as separations and purification in the chemical and associated industries. In these roles, it exhibits a remarkable efficiency as the international production is a little more than a million tons per year, with perhaps 2 million tones being in continuous use. Broadly AC has been used for three main purposes:
1. AC is dominantly used for purposes of adsorption in liquid-phase. The wide-ranging scenarios for $\mathrm{AC}$ are:

- Drinking water availability, to improve taste, smell and color including removal of chlorinated compounds and other volatile organic carbons (VOCs).

- Purification of ground water purity from contaminants coming from disused sites of heavy industries.

- Treatment of both industrial and municipal wastewater.

- Mining operations require feed water treatment, metallic ion adsorption (gold and other metals), adsorption of excess flotation reagents and adsorption of natural organic matter (NOM).

- Pharmaceutical processes, including purification of process water, use with fermentation broths and purification of many products.

- The food, beverage and oil industries for removal of color and unacceptable tastes.

- The dry-cleaning industries require purification of solvents.

- The electroplating industries require purification of wastewaters containing $\mathrm{Pb}, \mathrm{Cr}$, etc.

- Household water purification, cleaning of aquaria and use in oven-extract hoods.

Correspondence to: Seitkhan Azat, KazNU Al-Farabi, Faculty of Chemistry and Chemical Technology, Almaty, Kazakhstan; Tel: +74956493099; E-mail: seithan@mail.ru

Key words: carbonization, activation, nanostructures, sorption activity, ultimate composition, chromatography, Limonidin, BAC

Received: June 14, 2017; Accepted: July 23, 2017; Published: July 26, 2017 
- The sugar and sweetener industries need decolorization agents for production of white sugar, etc.

1. AC in different forms (granular, extruded, fiber or cloth) is used for production of pure gases in the chemical industry, to reduce pollutant gases to very low concentrations in a single stage, in protection against poisonous gases, in air conditioning, for removal of oil from compressed air, to separate gases in mixtures by sieving, etc.

2. Carbon materials have been used for some time in heterogeneous catalysis, acting as direct catalysts or as a catalyst support. Catalytic particles can be supported within the porosity to promote required catalytic conversions [4-7].

A set of strict requirements are imposed on the sorbent's material in liquid column chromatography. Firstly, column material should have sufficient strength and hardness with marginal dependence on the presence and composition of the eluent flow in the column. Secondly, the sorbent should have a well-developed uniform surface and narrow fractional composition. Thirdly, the sorbent should not enter into irreversible chemical interaction with both eluent components and isolated sample. A large number of inorganic and organic materials meet these requirements. Still, in terms of long-term stability of sorbent properties, reproducibility of its properties and quantity of specific surface area, it is observed that the suitable materials are limited to siliceous gel and, to a far lesser extent, aluminium oxide, which were most widely used during realization of the first historical variant of liquid chromatography - the normal-phase one.

As previously stated, attempts to use other inorganic materials as sorbents for liquid chromatography, such as zirconium oxide, calcined magnesia, titanium oxide, alumino silicate of various structures, inorganic salt and so on are also known. However, traditional silica gel sorbents, though being worse in some parameters, far exceeded these materials in terms of availability and reproducibility of properties and, moreover, had essentially lower price.
So far, most of sorbents (about 75\%) is produced on the basis of silica gel, $20 \%$ is accounted for polymers (polymethyl methacrylate, polystyrene divinylbenzene, polyethylenglycol, cellulose and others). Styrene-divinylbenzene copolymers are most commonly used. Poriferous polymers, unlike the silica gels, are stable over the entire $\mathrm{pH}$ range (0-14). Preference to these materials is given in on-exchange and ion chromatography. As noted above, the polymers and synthetic silica gels with wide pores are largely used in size exclusion chromatography.

Porous carbon sorbents occupy very small share (about 4\%) as sorbents for liquid chromatography. However, porous carbons are considered to be the most prospective sorbent materials due to their stability and unique selectivity, which is shown mainly to geometric isomers and stereoisomerides. This resulted in hybrid materials consisting of silochromes and microporous silica gels with a layer of pyrographite on the surface. A significant disadvantage of pure carbonbased materials for HPLC is their low mechanical strength, causing them to be difficult to use at high pressures [8]. There is thus a pressing need to create domestic porous carbon-based sorbents with high mechanical strength for the purposes of chromatographic separation of biologically active complexes and biological molecules [9-11]. Herbal substance "Limonidine" is isolated from plant roots of L. Gmelinii species of Limonium Mill genus of Plumbaginaceae family introduced into medical industry and State Pharmacopoeia of the Republic of Kazakhstan. There are industrial reserves of L. Gmelinii plants on the territory of the RK (Figure 1). It belongs to the halophyte, grows in all regions of the country in saline lands, unsuitable for agricultural purposes and grazing [12]. It is propagated vegetatively and by seed, stands out by rapid growth and high yields, and therefore, its reserves in nature will remain at the initial level subject to procurement rules and regulations (according to the instructions of Limonium provision). In addition, these plants may be subject to cultivated. They stand out for high adaptation indices, wide ecological amplitude, normalizing the content of sodium and calcium salts in the soil, high output of

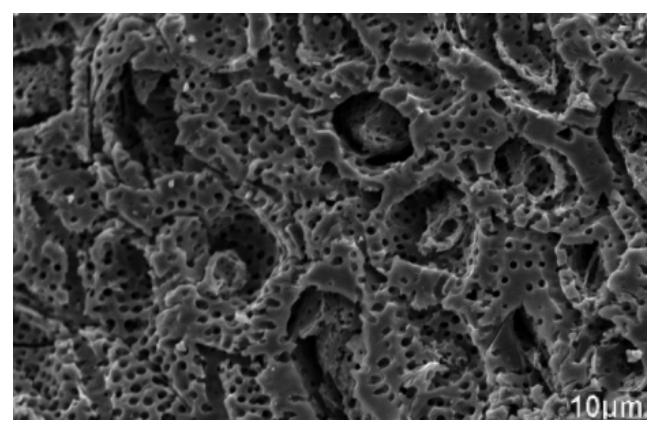

A: $\mathrm{RH}$

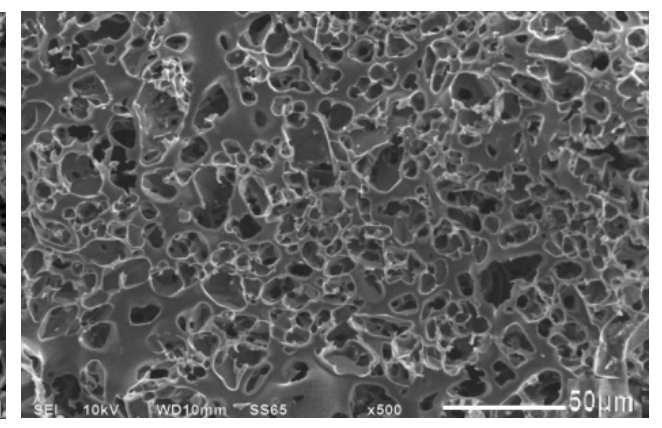

$\mathrm{B}: \mathrm{AK}$

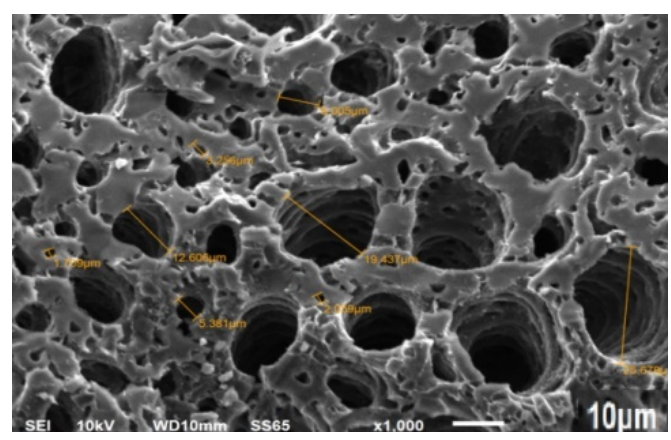

C: WS

Figure 1. Electron micrographs of the samples of carbon-based materials. 
"Limonidine" substance equaling to $30-40 \%$ of the weight of dried and processed raw material. Based on the above-mentioned, the roots of L. Gmelinii species are introduced into State Register of Medicinal Remedies of the RK and State Pharmacopoeia of the RK (SP RK, 2009). Production of "Limonidine" substance from plant roots of $L$. Gmelinii species is carried out by simple, economically and environmentally feasible technological scheme with high output at using aqueous ethylic alcohol solution, which is generated during production process, as exipent. Therefore, "Limonidine" substance is a highly efficient herbal substance, which can be used as an active agent during development of different new medicinal products. "Limonidine" substance contains all main classes of bioactive compounds of phenolic acid, flavans, flavonols both in the free-state and as glycoside, hydrolysable and condensed tannins. Moreover, it contains all $20 \alpha$ - amino acids known in nature, including eight indispensable amino acids, mono- and oligosaccharides, vitamins, traces and other biologically active substances. A total of 82 compounds is identified in "Limonidine" substance, of which 8 new isolated compounds are described in the world literature for the first time and are introduced into the world bank of new natural compounds, isolated from medicinal plants. The chemical study of "Limonidin" substance showed the presence of flavonols (myricetin, quercetin, izoramnetin, monomethyl ether of myricetin, and new flavanol not yet described in the world literature: 3,4,5,3',4',6'-hexahydroxyoxyflavon), their glycosides (miritsitrin, rutin, 3 - $\beta$-galactosylquercetin and 3 - $\beta$-galactosylmyricetin and other mono- and biosides, as well as 3- $\alpha$-galactosilquercetin and 3-O- $\alpha$-L-(2"-galloyl)- arabinopyranoside myricetin described for the first time), pyrogallol, gallic acid and ellagic acid. The main monomerical flavane is (-)-epigallocatechin gallate. There are also investigated new forms of flavan-3-ols not described in literature earlier: $3,5,7,3^{\prime}, 4^{\prime}, 6^{\prime}$ - hexahydroxyflavan, (-)-epigallocatechin$(4 \beta \rightarrow 8)-(-)-3,5,7,3^{\prime}, 4^{\prime}, 6^{\prime}$-hexahydroxyflavan and (+)-gallocatechin$(4 \alpha \rightarrow 8)-[(-)-\quad$ epigallocatechin]5-( $4 \beta \rightarrow 8)-(-)$-epigallocatechin gallate $[13,14]$. High efficiency of herbal substance "Limonidine" as an antioxidant, hepatoprotective, antiviral and immunomodulatory agent is explained by the presence of unique set of polyphenols in it, among which dominate the condensed tannins, represented in the substance by different forms of flavan-3-ols.

\section{Results and discussions}

Carrying conditions for the process of activation of carbon-based materials were selected in such a way that carbon-based material will have large specific surface area (which was measured using analyzer "Sorbtometr-M") and maintain high mechanical strength after activation. It was determined earlier that processing of carbon-based materials by inorganic activating agents is accompanied by increase in their specific surface area to $2,000 \mathrm{~m}^{2} / \mathrm{g}$. Change in the ratio of activating agent and rise of activation temperature to $650^{\circ} \mathrm{C}$ result in simultaneous material oxidation and its carbonization reaction. Joint impact of these two processes causes further growth of specific surface area to $1,200-2,100 \mathrm{~m}^{2} / \mathrm{g}$ (Table 1 ), but it reduces the mechanical strength of the samples.

As a result of activation of the samples the values of specific surface area and sorption capacity have significantly changed. If, prior to activation the sorption capacity of methylene blue of the samples was $0.07-0.10 \mathrm{~cm}^{3} / \mathrm{g}$, after activation the sorption capacity of the samples was $268.75-360 \mathrm{~cm}^{3} / \mathrm{g}$

Electron microscopy was used to identify the morphologic and structural characteristics of carbon-based materials. Studies were carried out using microscope Quanta 3D 200iDualSystem, FEI with integrated energy-dispersive microanalysis system.
Table 1. The specific surface area of the activated carbon samples.

\begin{tabular}{|c|c|c|c|}
\hline No & $\mathbf{T}^{0} \mathrm{C}$ & Sample & Specific surface area, $\mathrm{m}^{2} / \mathrm{g}$ \\
\hline 1 & 650 & $\begin{array}{l}\mathrm{WS} / \mathrm{KOH} \\
1 / 3\end{array}$ & 676,929 \\
\hline 2 & 650 & $\begin{array}{c}\mathrm{AK} / \mathrm{KOH} \\
1 / 2\end{array}$ & 373,53 \\
\hline 3 & 650 & $\begin{array}{l}\mathrm{RH} / \mathrm{KOH} \\
1 / 2\end{array}$ & 313,258 \\
\hline 4 & 650 & $\begin{array}{l}\mathrm{RH} \backslash \mathrm{KOH} \text { milled } \\
1 / 2\end{array}$ & 384,791 \\
\hline 5 & 650 & $\begin{array}{l}\mathrm{WS} / \mathrm{KOH} \\
1 / 2\end{array}$ & 290,677 \\
\hline 6 & 750 & $\begin{array}{l}\mathrm{WS} / \mathrm{H}_{3} \mathrm{PO}_{4} \\
1 / 2\end{array}$ & 793,748 \\
\hline 7 & 750 & $\begin{array}{c}\mathrm{RH} / \mathrm{H}_{3} \mathrm{PO}_{4} \\
1 / 2\end{array}$ & 739,68 \\
\hline 8 & 750 & $\begin{array}{c}\mathrm{RH} / \mathrm{H}_{3} \mathrm{PO}_{4} \\
1 / 3\end{array}$ & 634,9 \\
\hline 9 & 650 & $\begin{array}{l}\mathrm{WS} / \mathrm{KOH} \\
1 / 3\end{array}$ & 1276,301 \\
\hline 10 & 650 & $\begin{array}{c}\mathrm{RH} / \mathrm{KOH} \\
1 / 4\end{array}$ & 1233,5 \\
\hline 11 & 650 & $\begin{array}{l}\mathrm{WS} / \mathrm{KOH} \\
1 / 4\end{array}$ & 1652,5 \\
\hline 12 & 650 & $\begin{array}{c}\mathrm{RH} / \mathrm{KOH} \\
1 / 4\end{array}$ & 754,9 \\
\hline 13 & 650 & $\begin{array}{c}\mathrm{AK} / \mathrm{KOH} \\
1 / 4\end{array}$ & 1942,9 \\
\hline 14 & 650 & $\begin{array}{c}\mathrm{WS} / \mathrm{NaOH} \\
1 / 4\end{array}$ & 2099,3 \\
\hline 15 & 650 & $\begin{array}{c}\mathrm{AK} / \mathrm{NaOH} \\
1 / 4\end{array}$ & 1468,8 \\
\hline 16 & 650 & $\begin{array}{l}\text { not carbonized.AK/ZnCl } \\
1 / 2\end{array}$ & 753,5 \\
\hline 17 & 650 & $\begin{array}{c}\mathrm{AK} / \mathrm{KOH} \\
1 / 4\end{array}$ & 592,9 \\
\hline 18 & 650 & $\begin{array}{c}\mathrm{AK} / \mathrm{KOH} \\
1 / 4\end{array}$ & 785,42 \\
\hline 19 & 950 & $\begin{array}{c}\mathrm{RH} / \mathrm{K}_{2} \mathrm{CO}_{3} \\
1 / 2\end{array}$ & 475,2 \\
\hline
\end{tabular}

As can be seen from the figures $1 \mathrm{a}-\mathrm{c}$ all samples of carbon-based material have irregular and rough surface with high-porous structure (Figure 1).

Using modern energy-dispersion spectrometer of JED-2300 EDS type by JEOL (Japan), which is additional device of scanning electron microscope, the ultimate composition of carbon-based samples was determined prior to and after the activation. The study data is provided in Table 2.

As seen from the tables, following the carbonization the significant decrease in quantity of oxygen and sulfur occurs, which escape during the carbonization process affecting beneficially the quality of the carbonized material. At the same time, the percentage composition of carbon increases. If, prior to carbonization the carbon content accounts for an average of $\sim 62 \%$, after carbonization the carbon content is $\sim 91 \%$.

Further in this paper the fractionation of monomeric flavan-3-ols and proanthocyanidins in terms of dimeric, oligomeric and polymeric forms of flavan-3-ols was succeeded by using domestically produced nanostructured sorbent.

Technique is based on chromatographic separation of proanthocyanidin complex with the use of nanostructured sorbent, which is repeatedly washed with hot water from carbon dust. The column was filled with sorbent by both humid and dry methods. 
Table 2. The elemental composition of samples of activated carbon materials.

\begin{tabular}{|c|c|c|c|c|c|c|}
\hline $\begin{array}{c}\text { Elements } \\
\text { At\% }\end{array}$ & AK & WSh & RH & $\begin{array}{c}\text { AK } \\
\text { Activated }\end{array}$ & $\begin{array}{c}\text { WSh } \\
\text { Activated }\end{array}$ & $\begin{array}{c}\text { RH } \\
\text { Activated }\end{array}$ \\
\hline CK & 62,16 & 62,87 & 58,90 & 91,54 & 92,07 & 84,43 \\
\hline OK & 34,67 & 34,71 & 36,47 & 8,46 & 6,85 & 12,65 \\
\hline NaK & 1,54 & - & 1,59 & - & - & 0,89 \\
\hline SK & - & 0,73 & 1,97 & - & 0,33 & 0,85 \\
\hline KK & 0,92 & 0,17 & - & - & 0,48 & - \\
\hline PK & - & 0,66 & 1,07 & - & - & 1,17 \\
\hline FeK & 0,71 & 0,58 & - & - & 0.28 & - \\
\hline
\end{tabular}

Elution was carried out with chloroform, chloroform-acetone mixture with reduced amount of chloroform $(9: 1,8: 2,7: 3,6: 4,3: 7,1: 9)$, acetone, then with acetone-water mixture under different proportions of solvents (9:1, 8:2, 7:3, 5:5, 3:7, 1:9) and finally with water. All obtained fractions were concentrated, and then chromatographed on FN 11 paper using specific diagnostic developers. Chromatography was performed in sealed chamber by bottom-up technique on FN 11 paper. Dried chromatographs were processed using specific developers: vaporous ammonia, $1 \%$ aqueous solution of aluminium chloride, mixture of $5 \%$ sodium nitrite solution with $2 \%$ acetic acid solution, $1 \%$ aqueous solution of ferric ammonium sulfate, $1 \%$ vanillin solution in concentrated sulphuric acid. It was stated that under elution with chloroform nonpolar compounds (higher hydrocarbons, sterols, carbonic polyenoic acids) were separated, under acetone-water mixture flavonoids and terpens were separated, under acetone-water mixture initially monomeric forms of flavan-3-ols and their glycosides, and then di-, oligo- and polimeric forms of flavan-3-ols (proanthocyanidins) were separated, and under elution with water salts of inorganic and organic substances, carbohydrates and amino acids were separated. Separation of substances was controlled by special agents, hydrogen nitride and vanillin.

Qualitative reactions of the studied compounds with $1 \%$ solution of ferric ammonium sulfate demonstrate the presence of three vicinally arranged phenolic hydroxyl groups (complexes from dark blue to black color) in them, as further confirmed during their alkaline cleavage.

Fractions identical chromatographycally, which had equal fluorescence in visible and ultraviolet light, were united. These fractions were identified using authentic standards of samples during one-dimensional chromatography. Two-dimensional chromatography was used for them as well. Then the studied fractions were concentrated in mild conditions under vacuum. According to the chromatographic analysis and qualitative reactions, the complex of condensed tannins contains a mixture of 9 substances, representing different forms of flavan-3-ols.

Similar process of condensed tannins separation from compound by means of nanostructured sorbent was repeated over and over for its standardization.

Summarized complex of condensed tannins represents a crystalline matter of brown color with a bitter, astringent taste, and specific odour, soluble in water and aqueous alcohol solutions. It is insoluble in lipophilic solvents: benzene, chloroform, hexane, toluene.

\section{Comparative analysis of antioxidant activity}

Under invitro conditions the comparative analysis of antioxidant activity of "Limonidine" substance (indicated as sample 1) and proanthocyanidin fraction, representing a sum of different forms of flavan-3-ols (sample 4), was carried out. The intensity of lipid peroxidation in liver microsomes was estimated according to the content of TBA-active products. Malondialdehyde (MDA) concentration was determined based on the intensity of staining as a result of interaction with thiobarbituric acid (TBA) by the method of H.O. Ohkawa e.a. The results were statically processed using MicrosoftExcel program, calculating the simple average of the parameter, the mean square deviation, the simple average error. Taking into account the FischerStudent test, the recorded changes in indices were considered to be relevant at $\mathrm{p} \leq 0.05$.

The results of the experiments showed that both samples have a dose-dependent impact on the process of formation of TBA-active products in liver microsomes.

Table 3 contains data on determination of content of peroxide products in liver microsomes under the influence of increasing concentrations of extracts. It is obvious that by increasing the concentration of protein from 5 to $50 \mu \mathrm{gr}$ per $\mathrm{mg}$, the content of peroxide products in liver microsomes decreases. It should be noted that samples 1 and 4 show good antioxygenic properties.

Concentrations of extracts, showing 50\% inhibition of formation of lipid oxidation products (LOPs) are provided in Table 4. From the data resulted in table 4 it is visible that IC50 (median effective inhibition concentration) of preparation 1 and 4 amounts to 9.8 and $8.3 \mu \mathrm{gr} / \mathrm{mg}$ of protein accordingly.

Sample No.1 provided a dose-dependent reduction of LOP processes intensity. At $5 \mu \mathrm{gr}$ the level of MDA has decreased by $20 \%$, at $10 \mu \mathrm{gr}$ by $51 \%$, at $20 \mu \mathrm{gr}$ by $68 \%$ and at $50 \mu \mathrm{gr}$ it has decreased by $84.5 \%$ from initial level. Under the action of the extract in concentration of $5 \mu \mathrm{gr}$ the inhibition of LOP processes in 1.8 times was noted; further increse in extract concentration resulted in smoother reduction of the content of lipid peroxidation products. At $50 \mu \mathrm{gr}$ concentration a complete inhibition of peroxidation in liver microsomes, as evidenced by low content of MDA (17\%), was observed.

Following the comparison of the data obtained, it can be stated that the antioxidant properties of samples 1 and 4 are sufficiently close, indicating a dominant impact of condensed tannins in the substance.

\section{Conclusions}

By carbonization and activation in the presence of inorganic activating agents, vapour-gas and chemical activation of apricot kernel, walnut shells and rice husk, porous carbon-based materials with large specific surface area were obtained.

Analysis of low-temperature porometry of nitrogen for all samples revealed numerous specific surface areas, pore volume and pore radius. SEM data showed the presence of various micro- $(<2 \mathrm{~nm})$, meso- $(2-50$ $\mathrm{nm})$ and macropores $(>50 \mathrm{~nm})$ in all carbon-based materials. Samples treated with sodium hydroxide at a ratio of 1:4 have the largest specified

Table 3. Study of antioxidant properties (\%) Probe 1 and 4.

\begin{tabular}{|c|c|c|c|c|c|}
\hline \multirow{2}{*}{ Preparations } & \multicolumn{5}{|c|}{ Protein Concentration (ug / mg) } \\
\cline { 2 - 6 } & $\mathbf{0}$ & $\mathbf{5}$ & $\mathbf{1 0}$ & $\mathbf{2 0}$ & $\mathbf{5 0}$ \\
\hline 1 & 100 & $79,7 \pm 1,1$ & $49,0 \pm 0,6$ & $31,9 \pm 0,4$ & $15,5 \pm 0,2$ \\
\hline 4 & 100 & $56,7 \pm 1,1$ & $47,4 \pm 1,1$ & $33,0 \pm 0,5$ & $17,0 \pm 0,4$ \\
\hline
\end{tabular}

Table 4. Determination of IC50 values of extracts.

\begin{tabular}{|c|c|}
\hline Preparations & $\begin{array}{c}\text { IC50 (concentration of half-maximal } \\
\text { inhibition), } \mathbf{u g} / \mathbf{m g} \text { protein }\end{array}$ \\
\hline 1 & $9,8 \pm 1,3$ \\
\hline 4 & $8,3 \pm 1,2$ \\
\hline
\end{tabular}


surface area: $2,099.3 \mathrm{~cm}^{2} / \mathrm{g}$. Examination of adsorption capacity of the samples prior to and after the activation showed a significant change in value. If, prior to activation the samples showed the sorption capacity of $0.07-0.10 \mathrm{~cm}^{3} / \mathrm{g}$, after activation the sorption capacity of the samples was $268.75-360 \mathrm{~cm}^{3} / \mathrm{g}$. Proanthocyanidin complexes were separated using column chromatography with nanostructured sorbent.

Study of antioxidant activity of "Limonidine" substance and proanthocyanidin fraction, representing a sum of different forms of flavan-3-ols, carried out under invitro conditions showed that both samples have a dose-dependent impact on the process of formation of TBA-active products in liver microsomes.

\section{References}

1. Aygun A, Yenisoy-Karakas S, Duman I (2003) Production of granular activated carbon from fruit stones and nutshells and evaluation of their physical, chemical and adsorption properties. Micropor Mesopor Mater. 66: 189-195.

2. Zielke U, Huttinger KJ, Hoffman WP (1996) Carbon 34: 983.

3. Rodriguez-Reinoso F (1998) Carbon 36: 159.

4. Benaddi H, Bandosz TJ, Jagiello J, Schwarz JA, Rouzaud JN, et al. (2000) Surface Functionality and Porosity of Activated Carbons Obtained from Chemical Activation of Wood. Carbon 38, 669-674

5. Asma BM (2000) Apricot Production. Evin Ofset, Malatya, Turkey.
6. Fierro V, Fernandez VT, Montane, Celzard A (2008) Adsorption of phenol onto activated carbons having different textural and surface properties. Micropor Mesopor Mater. 111: 276-284

7. Basso MC, Cerrella EG, Cukierman AL (2002) Activated Carbons from a Rapidly Renewable Biosource for Removal of Cadmium (II) and Nickel (II) Ions from Dilute Aqueous Solutions. Ind Eng Chem Res. 41: 180-189.

8. Chizhkov VP, Boicov VN, Demin AV (2011) J Fizh. chemistry. 85:3. S. 565.

9. Kerimkulova AR, Mansurova BB, Gilmanov MK, Mansurov ZA (2011) Nanoporous Carbon Sorbent for Molecular_Sieve Chromatography of Lipoprotein Complex. Russian Journal of Physical Chemistry A. 85:6, 1004-1007.

10. Kerimkulova AR, Azat S, Mansurov ZA (2013) Nano-and macroporous carbons for separation and purification. IUMRS ICA. India Dec 16-20.

11. Kerimkulova AR, Sultanov NA, Gilmanov MK, Mansurov ZA, Abilov JA, et al. (2012) The use of nanostructured carbon adsorbents for the isolation of biomolecules and medicinal herbal substance. Herald sir. biological. 4(56). S 274-278.

12. Maznev NI (2012) Highly medicinal plants. Big Encyclopedia. Eksmo Moscow 483484

13. Zhusupova GE, Abilkaeva SA (2006) The dimeric proanthocyanidins from the roots of Limonium gmelinii III. Chemistry of Natural Compounds. 134-138.

14. Abilov JA, Zhusupova GE (2012) Limonidin botanical syrup with an anti-inflammatory effect. 1st USM - Kazakh National University Conference on: Challenges of teaching \& chemistry research in institutions of higher learning" Universiti Sains Malaysia, Penang. 1.

Copyright: (C)2017 Kerimkulova AR. This is an open-access article distributed under the terms of the Creative Commons Attribution License, which permits unrestricted use, distribution, and reproduction in any medium, provided the original author and source are credited. 